\title{
ecancerm \\ The first case of benign multicystic mesothelioma presenting as a splenic mass
}

\author{
Antonio D'Antonio', Carlo Baldi' ${ }^{1}$ Maria Addesso² and Carmine Napolitano ${ }^{3}$ \\ 1Department of Pathologic Anatomy, AOU S Giovanni di Dio e Ruggi D’Aragona, via S Leonardo, Salerno 84100, Italy \\ ${ }^{2}$ Unit of Pathologic Anatomy, Hospital Scarlato ASL SA, Pagani (SA) 84013, Italy \\ 'Unit of Surgery, AOU S Giovanni di Dio e Ruggi D’Aragona, via S Leonardo, Salerno 84100, Italy
}

Correspondence to: Antonio D’Antonio. Email: ada66@inwind.it

\begin{abstract}
Multicystic mesothelioma (MM) is a relatively rare tumour arising in the pelvic peritoneum of the tuboovarian region of young woman. Exceptionally, MM occurs on the serosal surfaces of various organs including kidney, bladder, lymph nodes, and liver. We report here the first case of MM wherein a 58-year-old woman with a previous history of endometriosis of the right ovary presented with a large multicystic mass of the spleen. The diagnosis of MM was made on a surgical specimen after splenectomy. A histopathologic examination is always necessary for the diagnosis of MM which should be differentiated from other lesions particularly from cystic lymphangioma. At one year follow-up, the patient had no evidence of recurrence. Despite the high frequency of local recurrences, MM is a benign lesion and 'en bloc' surgical excision with prolonged follow-ups is the treatment of choice.
\end{abstract}

Keywords: multicystic mesothelioma, spleen, peritoneum, immunohistochemistry, prognosis

Published: 04/10/2016

Received: 21/06/2016

ecancer 2016, 10:678 DOI: 10.3332/ecancer.2016.678

Copyright: $\odot$ the authors; licensee ecancermedicalscience. This is an Open Access article distributed under the terms of the Creative Commons Attribution License (http://creativecommons.org/licenses/by/3.0), which permits unrestricted use, distribution, and reproduction in any medium, provided the original work is properly cited. 


\section{Background}

Multicystic mesothelioma (MM), is a relatively rare tumour which occurs mainly in young women in their reproductive age [1-29]. MM arises in most instances from the mesothelial lining of the pelvic peritoneum, usually in the tuboovarian region. Secondary involvement of the serosa of other organs has been reported [12-14, 23]. This tumour has been given different names including benign cystic mesothelioma [5,18-20], multilocular peritoneal inclusion cyst [6, 15], postoperative peritoneal cyst [16], inflammatory inclusion cyst of peritoneum $[17]$, and others $[22,23]$. All these different terms reflect the unclear origin of the disease. The current consensus is that MM is not a true neoplasm, but a reactive proliferation because of trauma, surgery, or chronic inflammation [13, 15]. Up to date approximately 150 cases have been reported all over the world. We would like to report here the first case of MM originating in the spleen of the female patient with a previous diagnosis of endometriosis of the right ovary treated with splenectomy.

\section{Clinical case}

A 58-year-old woman with a surgical history of right oophorectomy for ovarian endometriosis presented with weakness and left flank pain with bulging of the left side of the abdomen. The tumour marker test showed normal findings ( $\alpha$-fetoprotein $0,9 \mathrm{ng} / \mathrm{mL}$, carcinoembryonic antigen 2,1 ng/mL), except for an elevated serum carbohydrate antigen of 125 (>625 U/mL). Contrast enhanced computed tomography (CT) of abdomen and pelvis showed a large multicystic mass of the spleen. A vascular proliferation of the spleen was clinically suspected and a surgical splenectomy was planned. A vascular proliferation of the spleen was clinically suspected and a splenectomy was carried out. Patient had an uneventful postoperative period and was discharged in postoperative day (POD) seven. Around three and six months after surgery, the patient had no complaints and ultrasonography of abdomen was normal. At one year after surgery, a CT scan showed no disease recurrence.

\section{Materials and methods}

The tissues were fixed in $4 \%$ buffered formalin, routinely processed, and embedded in paraffin. After which 3-4 $\mu \mathrm{m}$-thick sections were stained with haematoxylin and eosin, Immunohistochemistry was conducted with a Benchmark automated staining system (Ventana Medical Systems, Tucson, AZ) using Ventana monoclonal antibodies (calretinin 1:2000; mesothelial Ag HMBE-1 1:50; CD31 1.100; CD34 1.50; FVIII 1:200; smooth muscle actin [SMA] 1:40; pancytokeratin [CKpan] 1:100; CK5/6 1:100; oestrogen receptor [ER] 1:100). Appropriate positive and negative controls were used.

\section{Results}

The spleen measured $20 \times 10 \mathrm{~cm}$ and the cut sections showed a large mass with numerous macrocystic and microcystic spaces filled by gelatinous or haemorrhagic fluid (Figure 1). Histologically the macrocystic and microcystic spaces were lined by flattened endothelial-like cells or cuboidal cells with bland round nuclei (Figure 2a). Some areas showed a lymphangioma-like pattern for the presence of cystic spaces contained erythrocytes (Figure 2b). Tubular and gland-like spaces with clear epithelioid lining cells were also present (Figure 2c). Atypia and mitoses were absent. A cuboidal epithelium with squamous metaplasia lined some cystic nodules filled with eosinophilic proteinaceous material (Figure 2d). In all cases immunohistochemistry revealed diffuse positivity of the lining epithelium for CKPan, calretinin (Figure 3a), HMBE-1, CK5/6, and ER (Figure 3b) with negativity for CD 34, CD31, FVIII.

\section{Discussion}

Multicystic mesothelioma (MM) is a relatively rare but well-known clinicopathologic entity, first described in 1979 by Menemeyer and Smith [1]. To date approximately 150 cases have been reported in the literature [1-29]. Typically MM arises from the pelvic peritoneum around 
the tuboovarian region, and it occurs more frequently in young women $[2,13,15,18]$. A localisation on the serosal surfaces of the pelvic viscera or peritoneum of various organs including appendix [12], lymph nodes, liver [13], and kidney [14]. Although MM occurs most frequently in women in their reproductive age, people of any age and sex can be affected. Clinically MM is asymptomatic and only in presence of large masses of disseminated forms may be associated with pain and ascites [18]. Macroscopically surgical specimen is represented by uniloculated or multiloculated thin-walled cystic nodules ranging few millimeters to several centimeters filled of clear, gelatinous, or haemorrhagic fluid [2-13]. Occasionally, the cystic wall contained solid mural nodules [15]. Histologically the cystic spaces are separated by a fibrous, edematous, or myxoid stroma, with a rich vascular network. Tubular-like or gland-like spaces can be present. These spaces are lined by an endothelial-like epithelium or cuboidal epithelioid-like cells with clear cytoplasm [6, 13]; squamous metaplasia is present in some cases [6]. A differential diagnosis should also include cystic lymphangioma which generally spares the pelvis and histologically shows bundles of smooth muscle and lymphoid aggregates in the cystic wall, absent in the MM. Further in the spleen because of the presence of a multicystic lesion, a vascular proliferation (haemangioma, haemangiomatosis, angiosarcoma) should always be excluded [29]. In some cases MM may show a haemangioma-like or lymphagioma-like pattern with cystic spaces containing haemorrhagic fluid and haemosiderin in the stroma. Immunohistochemistry helps in the differential diagnosis. MM is positive for calretinin and negative for endothelial markers as CD31, CD34, and F-VIII. The absence of atypia and few or absent mitosis are the diagnostic clue to differentiated MM from malignant mesothelioma and other malignant epithelial neoplasms (for example in cases of MM characterised by tubular spaces with clear cells). Though these should be done in association with immunohistochemistry. The pathogenesis of MM is controversial and remains unclear. Some authors believe that MM is a true tumour because they have high tendency to recur locally after surgical resection. The literature, however, tells that only two cases have been reported of malignant transformation, [30-31] and only one death was reported because of this lesion [32]. The majority of cases have an excellent prognosis and probably the presence of local recurrences is because of the number of cystic lesions and extension of disease that makes surgical resection very difficult. We, as other authors, favour a reactive nature of MM because of various factors that may promote the proliferation of mesothelium with formation of multiple uni or multilocular cysts. These then go on to form large pelvic or intra-abdominal masses or visceral nodules. In fact most patients presented has had previous history of either abdominal surgery, pelvic inflammation, trauma [6,13,15-17], or an association with endometriosis [33]. The therapy of MM is surgery. The complete excision of cystic masses if possible may prevent recurrences $[6,11,34,35]$ Recurrences occur more frequently in large masses [36] or disseminated disease and treated by hormonal therapy [37], hyperthermic intraperitoneal chemotherapy using cisplatin or doxorubicin [38], and sclerotherapy [1-10, 39]. In literature, there have been some cases reported of MM positivity for oestrogen receptor [40]. The influence of oestrogen receptor on MM pathogenesis and cyst growth is not well understood. Although immunohistochemical detection of sex hormone receptors in MM is uncommon [40], the focal presence of ER and/or PR in these cases have been used by some authors as support for a therapy with gonadotropin-releasing hormone agonist and the anti-oestrogen agent [41-42]. The biological rationale for this response, however, remains unexplained.

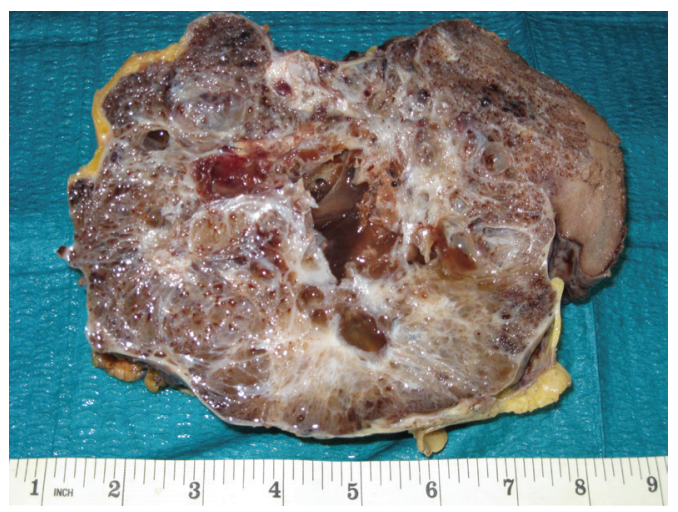

Figure 1. The cut surface of the spleen showed a large mass with numerous macrocystic and microcystic spaces filled by gelatinous or haemorrhagic fluid. 


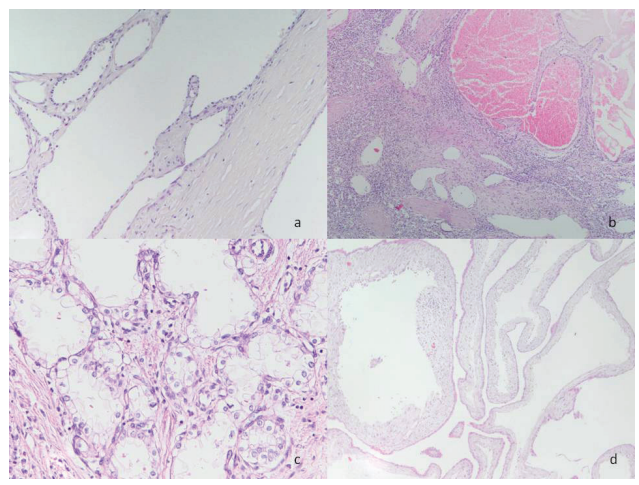

Figure 2a. The cystic spaces were lined by flattened endothelial-like cells or cuboidal cells with bland round nuclei. (HE 20x). Figure 2b. A lymphangioma-like pattern was also evident (HE 10x).

Figure 2c. Note tubular and gland-like spaces with clear epithelioid lining cells (HE 40x).

Figure 2d. Some cyst showed squamous metaplasia (HE 20x) .

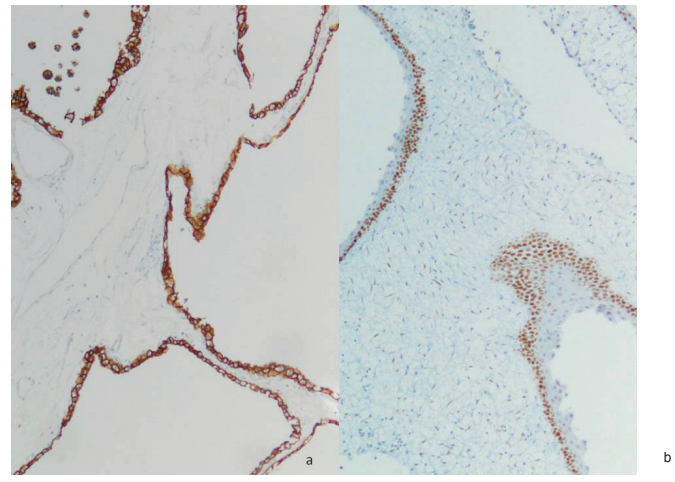

Figure 3a. Strong immunorectivity of the lining cells with calretinin (immunoperoxydase 20x).

Figure 3b. Some cyst showed positive nuclei for ER (immunoperoxydase 20x).

\section{Conclusions}

Multicystic mesothelioma is a benign and reactive lesion that can mimic many different disease entities including ovarian malignancies and cystic lymphangioma on imaging, and therefore histopathologic examination is always necessary for the diagnosis. Surgery is reported to be the only effective treatment for MM with a high risk of local recurrence if not completely excised. Further surgery, prolonged follow up of these pateints is necessary.

\section{Conflicts of interest}

The authors declare that they do not have any financial or potential conflicts of interest of any kind. 


\section{Authors' contributions}

AD proposed the study. CB and MA performed the research and wrote the first draft. CN collected and analysed the data. All authors contributed to the design and interpretation of the study and to further drafts. AD is the guarantor.

\section{Funding}

None.

\section{Ethical approval}

Not needed.

\section{References}

1. Mennemeyer R and Smith M (1979) Multicystic, peritoneal mesothelioma: a report with electron microscopy of a case mimicking intra-abdominal cystic hygroma (lymphangioma) Cancer 44(2) 692-8 PMID: 476578

2. Weiss SW and Tavassoli FA. (1988) Multicystic mesotelioma Am J Surg Pathol 12(10) 737-47 DOI: 10.1097/00000478-198810000$\underline{00001}$ PMID: $\underline{3421410}$

3. Schneider $\mathrm{V}$ et al (1983) Benign cystic mesothelioma involving the female genital tract: report of four cases Am J Obstet Gynecol 145(3) 355-9 DOI: $\underline{10.1016 / 0002-9378(83) 90724-X ~ P M I D: ~} \underline{6824025}$

4. Bhandarkar DS et al (1993) Benign cystic peritoneal mesothelioma J Clin Pathol 46(9) 867-8 DOI: 10.1136/jcp.46.9.867 PMID: $\underline{8227441}$ PMCID: $\underline{501528}$

5. Raafat F and Egan M (1988) Benign cystic mesothelioma of peritoneum: immunohistochemical and ultrastructural features in a child Paediatr Pathol 8(3) 321-9 DOI: 10.3109/15513818809042975

6. Ross MJ, Welch WR and Scully RE (1989) Multilocular peritoneal inclusion cysts (so-called cystic mesotheliomas) Cancer 64(6) 1336-46 PMID: 2766227

7. Katsube Y, Mukai K and Silverberg SG (1982) Cystic mesothelioma of the peritoneum: a report of five cases and a review of the literature Cancer 50(8) 1615-22 PMID: 7116294

8. Bakhshi GD et al (2013) Retroperitoneal approach for recurrent benign multicystic peritoneal mesothelioma Clin Pract 3(1) e3

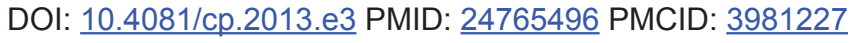

9. Tentes AA et al (2012) Multicystic peritoneal mesothelioma Am J Case Rep 13 262-4 DOI: 10.12659/AJCR.883523 PMID: 23569544 PMCID: $\underline{3615971}$

10. Hong $\mathrm{JH}$ et al (2013) Multicystic benign mesothelioma of the pelvic peritoneum presenting as acute abdominal pain in a young woman Obstet Gynecol Sci 56(2) 126-9 DOI: 10.5468/OGS.2013.56.2.126 PMID: 24327991 PMCID: $\underline{3784095}$

11. Safioleas MC et al (2006) Benign multicystic peritoneal mesothelioma: a case report and review of the literature World J Gastroenterol 12(35) 5739-42 DOI: 10.3748/wjg.v12.i35.5739 PMID: 17007034 PMCID: 4088182 
12. O'Connor DB, Beddy D and Aremu MA (2010) Benign cystic mesothelioma of the appendix presenting in a woman: a case report J Med Case Reports 4394 DOI: 10.1186/1752-1947-4-394

13. Di Blasi A et al (2004) Multicystic mesotelioma of the liver with secondary involvement of peritoneum and inguinal region Int $J$ Surg Pathol 12(1) 87-91 DOI: $10.1177 / 106689690401200116$ PMID: 14765281

14. Marrano D et al (1983) Cystic lesion of the kidney with ultrastructural evidence of mesothelial origin Ital J Surg Sci 13(4) 323-8 PMID: $\underline{671898}$

15. McFadden DE and Clement PB (1986) Peritoneal inclusion cysts with mural mesothelial proliferation: A clinicopathological analysis of six cases Am J Surg Pathol 10(12) 844-54 DOI: 10.1097/00000478-198612000-00003 PMID: 3789251

16. Gussman D, Thickman D and Wheeler JE (1986) Postoperative peritoneal cysts Obstet Gynecol 68 Suppl:53S-5S PMID: $\underline{3737078}$

17. Lees RF et al (1978) Inflammatory cysts of the pelvic peritoneum AJR 131(4) 633-6 DOI: 10.2214/ajr.131.4.633 PMID: 102153

18. Elbouhaddouti $\mathrm{H}$ et al (2013) Benign cystic mesothelioma of the peritoneum: a case report and literature review World $\mathrm{J}$ Emerg Surg 8(1) 43 DOI: 10.1186/1749-7922-8-43 PMID: 24120115 PMCID: $\underline{3853709}$

19. Tuncer AA et al (2016) Benign cystic mesothelioma in a child: case report and review of the literature Balkan Med J 33(2) 232-4 DOI: 10.5152/balkanmedj.2015.15886 PMID: 27403396 PMCID: 4924971

20. Shin HD and Kim SB Benign cystic mesothelioma misdiagnosed as peritoneal carcinomatosis Case Rep Gastroenterol 10(1) 115-120 PMID: 27403112 PMCID: 4929387

22. Lee $\mathrm{R}$ et al (2016) Benign multicystic peritoneal mesothelioma: AIRP best cases in radiologic-pathologic correlation Radio-

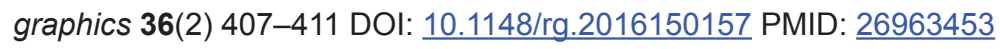

23. Occhionorelli $S$ et al (2016) Benign multicystic mesothelioma of peritoneum complicating acute appendicitis in a man: a case report J Med Case Rep 1044 DOI: 10.1186/s13256-016-0826-6 PMID: 26922647 PMCID: 4769818

24. lacoponi $S$ et al (2015) Asymptomatic peritoneal carcinomatosis originating from benign cystic peritoneal mesothelioma Ecancermedicalscience 9605 DOI: 10.3332/ecancer.2015.605 PMID: 26715942 PMCID: 4679213

25. Durell J et al (2016) Pediatric benign cystic peritoneal mesothelioma J Pediatr Adolesc Gynecol 29(2) e33-4 DOI: 10.1016/j. jpag.2015.10.018

26. Jerraya $\mathrm{H}$ et al.(2016) Benign multicystic peritoneal mesothelioma presenting as a ghost abdominal mass Diagn Interv Imaging 97(3) 361-3 DOI: 10.1016/j.diii.2015.08.005

27. Ianieri MM et al (2016) Incidental benign cystic mesothelioma of the peritoneum: a case report J Obstet Gynaecol 36(1) 135-6 DOI: $\underline{10.3109 / 01443615.2015 .1033387}$

28. Tamhankar VA (2015) Multicystic benign mesothelioma complicating pregnancy Case Rep Obstet Gynecol 2015687183 PMID: 26345310 PMCID: 4546733

29. D'Antonio A et al (2002) Splenic hemangiomatosis. A report of two cases and review of literature Adv Clin Path 6 (3-4) 119-24

30. Singh A et al (2013) Multicystic peritoneal mesothelioma: not always a benign disease Singapore Med J 54(4) e76-e78 DOI: 10.11622/smedj.2013085 PMID: 23624458

31. Sethna K et al (2003) Peritoneal cystic mesothelioma: a case series Tumori 89(1) 31-5 PMID: 12729358

32. González-Moreno S et al (2002) Malignant transformation of "benign" cystic mesothelioma of the peritoneum J Surg Oncol 79(4) 243-51 DOI: 10.1002/jso.10081 PMID: 11920782 
33. Kurisu Y et al (2011) Multicystic mesothelioma caused by endometriosis: $\mathbf{2}$ cases reports and review of literature Int $J$ Gynecol Pathol 30(2) 163-5 DOI: 10.1097/PGP.0b013e3181f99def PMID: 21293283

34. Wang TB et al (2013) Diagnosis and treatment of benign multicystic peritoneal mesothelioma Word J Gastroenterol 19(39) 6689-92 DOI: 10.3748/wjg.v19.i39.6689

35. Cavallaro A et al (2011) Cystic peritoneal mesotelioma: report a case Surg Today 41(1) 141-6 DOI: 10.1007/s00595-010-4301-5

36. Häfner M et al (2002) Giant benign cystic mesothelioma: a case report and review of literature Eur J Gastroenterol Hepatol 14(1) 77-80 DOI: 10.1097/00042737-200201000-00013 PMID: 11782579

37. Letterie GS and Yon JL (1998) The antiestrogen tamoxifen in the treatment of recurrent benign cystic mesothelioma Gynecol Oncol. 70(1) 131-3 DOI: 10.1006/gyno.1998.5031 PMID: 9698490

38. Park BJ et al (1999) Treatment of primary peritoneal mesothelioma by continuous hyperthermic peritoneal perfusion (CHPP) Ann Surg Oncol 6(6) 582-90 DOI: 10.1007/s10434-999-0582-6 PMID: 10493628

39. Benson RC Jr and Williams TH (1990) Peritoneal cystic mesothelioma: successful treatment of a difficult disease $J$ Urol 143(2) 347-8 PMID: 2299728

40. Sawh RN et al (2003) Benign cystic mesothelioma of the peritoneum: a clinicopathologic study of 17 cases and immunohistochemical analysis of estrogen and progesterone receptor status Hum Pathol 34(4) 369-74 DOI: 10.1053/hupa.2003.31 PMID: $\underline{12733118}$

41. Letterie GS and Yon JL (1995) Use of a long-acting GnRH agonist for benign cystic mesothelioma Obstet Gynecol 85 (5 Pt 2) 901-3 DOI: 10.1016/0029-7844(94)00431-C PMID: $\underline{7724156}$

42. Takeuchi $\mathrm{K}$ et al (1998) Conservative management of post-operative peritoneal cysts associated with endometriosis Int J Gynaecol Obstet 60(2) 151-4 DOI: 10.1016/S0020-7292(97)00253-1 PMID: 9509953 